\section{P-78 A STUDY TO INVESTIGATE PARENTAL SATISFACTION WITH THE ALLOCATION OF RESPITE BY A CHILDREN'S HOSPICE}

Carol Wylde. Brian House Children's Hospice, Blackpool, UK

10.1136/bmjspcare-2018-hospiceabs. 103

This study explored the opinion and understanding of parents whose children received respite care from a children's hospice as to how it is allocated to their child and their satisfaction with what they receive.

Caring for a child with a life-limiting illness has a profound impact on every dimension of family life. Providing appropriate respite care is of vital importance in helping parents cope with the constant demands of caring for these children.

The research adopted a mixed methods approach. The study invited all parents to contribute to the research by completing a questionnaire and participating in semi-structured interviews. The combination of the two data collection methods gave rise to six broad themes. Analysis of the data received contributed to the knowledge required to make change and improvements to practice.

The results showed parents liked the perceived informality of the current method used to allocate respite care, preferring it to a more formal assessment. Parents valued the relationship that developed with the hospice, felt fairly treated and expressed degrees of satisfaction with the respite care their child received. However, there was a lack of knowledge about the allocation of respite care. The interviews highlighted the complexity of the relationship parents have with the hospice which could prevent them from articulating concerns.

Knowledge gained from the research and critical reflection on practice has meant changes have been made to the allocation of respite care. The children's hospice must constantly question the effectiveness of the model used to allocate respite care. It should be equitable, consistent, transparent and objective, whilst recognising the uniqueness of each family. A clarity of information provided will allow an understanding of the care the hospice can provide alongside the organisational constraints that are integral to the allocation process.

\section{P-79 IMPLEMENTING A TISSUE INJURY PREVENTION AND MANAGEMENT TOOL IN A CHILDREN'S HOSPICE}

${ }^{1}$ Patricia Clarkson, 'Zoe Pilborough, ${ }^{1}$ Jackie Cooke, ${ }^{2}$ Katie Warburton. ${ }^{1}$ Derian House Children's Hospice, Preston, UK; ${ }^{2}$ UCLAN, Preston, UK

\subsection{6/bmjspcare-2018-hospiceabs.104}

Aims The National Institute for Health and Care Excellence recommend that a skin assessment is carried out for all neonates, children and young people at risk of developing a pressure ulcer.

The Braden Scale for Predicting Pressure Ulcer Risk, is a tool developed for the purpose of helping health professionals, especially nurses, assess a patient's risk of developing a pressure ulcer, with the Braden Q Scale being reviewed as an appropriate tool in children's nursing (Noonan, Quigley \& Curley, 2011).

'The Pink Pack' a tool, based on the Braden Q and Braden Scales, was developed for use in the children's hospice to ensure that all children and young people were assessed and care was implemented to prevent or manage tissue injury.
Methods The tool was implemented as a compulsory part of children's and young people's care plans following staff awareness training and staff room reminders. An audit was carried out to assess the usage of the tool for children and young people admitted to the children's hospice within a threemonth period. Notes were selected at random.

Results (or, in the case of on-going studies, progress to date or interim findings). An interim audit was conducted to assess the adoption and accurate completion of the tool. 22 care plans were reviewed, $100 \%$ had the Braden scale score sheet completed, 55\% had this completed on admission, 55\% had a treatment plan completed, $90 \%$ had an appropriate action plan, 33\% of children requiring a turning chart had one, the evaluation of care was completed on every shift during a child's admission in 33\% of cases.

Conclusions Further training and a repeat audit have been arranged to ensure all children and young people have a Braden scale assessment on admission which will result in an action plan where appropriate and daily evaluation of care.

\section{P-80 TRANSITION IN REALITY: END OF LIFE CARE FOR AN ADOLESCENT WITH HUNTINGTON'S IN AN ADULT HOSPICE}

${ }^{1,2}$ Damien McMullan, ${ }^{1}$ Yvonne Martin, ${ }^{2}$ Conn Haughey, ${ }^{2}$ Heather McCluggage, ${ }^{1}$ Paul Mclvor, ${ }^{2}$ Neil Corrigan. ${ }^{1}$ Foyle Hospice, Derry-Londonderry, UK; ${ }^{2}$ Western Health and Social Care Trust, Derry-Londonderry, UK

\subsection{6/bmjspcare-2018-hospiceabs.105}

Background A 17 year old with juvenile onset Huntington's chorea was admitted to an adult hospice in Northern Ireland for symptom management and possible end of life care. The patient had been known to adult palliative care services in the local hospital for approximately 10 months while under the care of the paediatric team and GP. The potential need for hospice admission for end of life care was recognised, but the nearest children's hospice was far away and so admission to the local adult hospice was explored and facilitated.

Aim To provide the adolescent patient and family with local hospice care.

Methods A timebound, patient-named application for variation of age registration was successful with the Regulation and Quality Improvement Authority. The admission was planned collaboratively between paediatric and adult palliative care services. This joint-working continued following admission to the adult hospice.

Outcome The initial move to the adult hospice presented challenges including recognition of dying in an adolescent; the patient's limited communication and distressing symptoms; adjustment of family to a different care setting; staff anxieties with looking after a dying adolescent. Symptoms were more controlled and the patient died, with family there, almost two weeks following admission.

Conclusion Flexibility by adult hospices regarding age restriction can help dying adolescents and their families to have access to inpatient hospice services when children's hospices are far away. This may become more relevant as patient numbers increase (Together for Short Lives, 2015). Good communication and collaborative working by paediatric and adult palliative care services are crucial in overcoming the challenges, easing staff anxiety and in maintaining the young person at the centre. 